\title{
Liver stiffness is not associated with short- and long-term plasma HIV RNA replication in immunocompetent patients with HIV infection and with HIV/HCV coinfection
}

\author{
Saverio Giuseppe Parisi ${ }^{a}$, Monica Basso ${ }^{a}$, Carlo Mengolia, Renzo Scaggiante ${ }^{b}$, Samantha Andreis ${ }^{a}$, \\ Marzia Maria Franzetti ${ }^{b}$ Anna Maria Cattelan', Daniela Zago a, Mario Crucianic, Massimo Andreonid, \\ Sara Piovesan ${ }^{a}$, Giorgio Palùa, Alfredo Albertia \\ University of Padova; Padova Hospital, Center of Diffuse Disease, Verona; Tor Vergata University of Rome, Italy
}

\section{Abstract}

Background Human immunodeficiency virus (HIV) may be directly responsible for liver damage but there are contrasting data regarding the influence of detectable plasma viremia. We analyzed the influence of plasma HIV RNA (pHIV) detectability and of other clinical and viro-immunological variables on liver stiffness (LS) measurement in adult immunocompetent HIV-monoinfected patients and in patients coinfected with hepatitis $\mathrm{C}$ virus (HCV).

Methods Logistic regression analysis was performed using the value of LS>7.1 $\mathrm{kPa}$ as the dependent variable. A linear regression model was applied using LS measurement after $\log _{10}$ transformation (lkpa) as the dependent variable and we analyzed the predicted values versus the observed lkpa values; pHIV was classified as detectable or undetectable in the 12- and 36-month study periods before LS measurement.

Results We studied 251 patients (178 with HIV monoinfection), most of whom were on antiviral treatment; 36-month study time was available for 154 subjects. The mean CD4+ cell count was 634 cells $/ \mathrm{mm}^{3}$ in HIV-monoinfected patients and $606 \mathrm{cells} / \mathrm{mm}^{3}$ in coinfected patients. No difference in LS was found between patients with detectable or undetectable pHIV in either the 12- or the 36-month study period before transient elastography. The mean LS was higher in $\mathrm{HIV} / \mathrm{HCV}$ coinfected patients $(\mathrm{P}<0.0001)$ than in the HIV-monoinfected subjects; lkpa was positively correlated with $\mathrm{HCV}$ coinfection $(\mathrm{P}<0.0001)$ and aspartate aminotransferase levels $(\mathrm{P}<0.0001)$. Detectable pHIV failed to reach significance. Eight HIV-monoinfected patients had a predicted LS measurement lower than the observed one, while eight patients had the opposite result.

Conclusion LS was not correlated with ongoing HIV replication during the 12- and 36-month study periods in immunocompetent $\mathrm{HIV}$-monoinfected and $\mathrm{HIV} / \mathrm{HCV}$-coinfected patients.

Keywords Liver stiffness, HIV RNA, immunocompetent

Ann Gastroenterol 2017; 30 (5): 1-8

\footnotetext{
${ }^{\mathrm{a} D e p a r t m e n t ~ o f ~ M o l e c u l a r ~ M e d i c i n e, ~ U n i v e r s i t y ~ o f ~ P a d o v a, ~ P a d o v a ~}$ (Saverio Giuseppe Parisi, Monica Basso, Carlo Mengoli, Samantha Andreis, Daniela Zago, Sara Piovesan, Giorgio Palù, Alfredo Alberti); 'Infectious Disease Unit, Padova Hospital, Padova (Renzo Scaggiante, Marzia Maria Franzetti, Anna Maria Cattelan); ${ }^{\mathrm{c} C e n t e r}$ of Diffusive Diseases, ULSS 20, Verona (Mario Cruciani); ${ }^{\mathrm{d} C l i n i c a l ~ I n f e c t i o u s ~}$ Diseases, Tor Vergata University of Rome, Rome (Massimo Andreoni), Italy

Conflict of Interest: None
}

Received 19 April 2017; accepted 6 June 2017; published online 4 July 2017

DOI: https://doi.org/10.20524/aog.2017.0175

\section{Introduction}

Chronic liver disease is a major cause of morbidity and mortality in human immunodeficiency virus (HIV)-positive patients, and coinfection with hepatitis $\mathrm{C}$ virus ( $\mathrm{HCV}$ ) is one of the most clinically important comorbidities [1]. However, many other factors, such as alcohol abuse, drug-related hepatotoxicity and nonalcoholic fatty liver disease, may also be responsible for liver damage [2,3]. This scenario is evolving as a result of the availability of direct-acting antivirals for the treatment of $\mathrm{HCV}$ infection and the current minimal exposure to antiretroviral drugs with a potentially hepatotoxic profile, 
such as didanosine, stavudine or zidovudine [4-6]. HIV may be directly responsible for liver damage; Kupffer cells, hepatocytes, and human stellate cells (HSCs) do not express CD4 receptors, and HIV cannot infect these cells, but the virus can stimulate HSCs through a $\mathrm{C}$ - $\mathrm{C}$ chemokine receptor type 5- or C-X-C chemokine receptor type 4-dependent pathway. HSCs are key cells involved in the progression of fibrosis: transforming growth factor- $\beta$, secreted by human peripheral blood mononuclear cells infected by HIV-1, was found to promote HSC modulation in an in vitro model $[7,8]$. Updated guidelines recommend that antiretroviral treatment (ART) should be started in all HIV-infected subjects with detectable plasma HIV viremia, regardless of CD4+ cell count; successful plasma HIV viremia suppression is achieved in most patients, but long-term efficacy may be suboptimal [6,9].

Liver fibrosis in HIV-positive patients is a multifactorial process; parameters modifiable over time (e.g., HBV-DNA and HCV-RNA detectability or undetectability) or parameters not modifiable over time (e.g., sex) may influence liver fibrosis $[3,10,11]$. The measurement of liver stiffness (LS) by transient elastography (TE) represents a rapid and noninvasive method for predicting liver fibrosis, and the result, which is expressed in kilopascals $(\mathrm{kPa})$, is available immediately; this imaging modality is highly accurate in the detection of moderate fibrosis and cirrhosis in patients with HIV/HCV coinfection [12]. Abnormal LS values were found in a percentage of HIV-monoinfected patients, ranging from $41.9 \%$ (LS values $>5.3 \mathrm{kPa}$ were considered abnormal) to $11.2 \%$ (LS values $\geq 7.2 \mathrm{kPa}$ were considered abnormal) [13-15].

TE was shown to be more reliable than the aspartate aminotransferase (AST)-to-platelet ratio index and the Fibrosis-4 score (FIB-4) in the staging of liver fibrosis in $\mathrm{HIV} / \mathrm{HCV}$ coinfected patients; both indices include platelet count, which may be lower in viremic HIV-positive patients because of HIV-related thrombocytopenia [16,17]. The first aim of this study was to describe the demographic and viro-immunological parameters that influence TE results in a cohort of immunocompetent HIV-monoinfected patients and $\mathrm{HIV} / \mathrm{HCV}$-coinfected patients; the second aim of this study was to evaluate the reliability of a model (linear predictor) that included clinical variables in predicting LS value.

\section{Patients and methods}

We retrospectively enrolled patients into this study based on the following eligibility criteria: 1) age over 18 years; 2) diagnosis of chronic HIV infection; 3) hepatitis

Correspondence to: Saverio G. Parisi, Department of Molecular Medicine, University of Padova, Via Gabelli 63, 35121 Padova, Italy, Tel.: +390498 272344, Fax: +390498272355,

e-mail: saverio.parisi@unipd.it

The work was conducted at the Department of Molecular Medicine, University of Padova, Padova, Italy

Saverio Giuseppe Parisi and Monica Basso contributed equally to this work
B serum antigen (HBsAg)-negative; 4) HCV treatmentnaïve or previously treated relapsers or non-responders; 5) regular viro-immunological follow up of the HIV disease during at least the 12 months before TE; 6) no acute HCV infection; 7) no alcohol abuse; 8) no didanosine, stavudine or zidovudine therapy; and 9) valid TE performed between December 1, 2013, and September 30, 2015. Patients were excluded from the study if they showed a sustained virological response (SVR), experienced a spontaneous clearance of HCV, or had other known causes of liver disease or previous liver transplantation. Alcohol abuse was defined as the daily consumption of alcohol in doses of more than $20 \mathrm{~g} /$ day for women and more than $30 \mathrm{~g} /$ day for men. This study was conducted in accordance with local legislation and received approval from the local Ethics Committee of Padova University Hospital (61946/15). Anonymous data were collected retrospectively.

Patients were either untreated for HIV infection or received ART according to the current international guidelines. Decisions on HIV therapy were made at the discretion of the treating physician; there were no restrictions on CD4+ cell count.

Patients were classified based on plasma HIV viremia (detectable or undetectable when TE was performed and in the 12 months and the 36 months before TE) and on the presence of $\mathrm{HCV}$ infection (patients were either HCV-positive or $\mathrm{HCV}$-negative). We defined $\mathrm{T} 0$ as the study time corresponding to the execution of TE, T1 as the study time corresponding to the 12-month period (short term) before TE and T2 as the study time corresponding to the 36-month period (long term) before TE. Plasma HIV viremia data during T2 were available for a subgroup of subjects.

\section{Study of HIV and HCV infection}

Plasma HIV-1 RNA levels were measured using blood samples at all visits; regular monitoring was defined as a visit frequency of at least every four months. We considered plasma HIV viremia to be undetectable when the viral load was below the limit of 50 copies/mL [6]. Only a single viral blip (an increase in the HIV RNA plasma viral load above 50 copies/mL but below 500 copies/mL, followed by an undetectable HIV RNA) was tolerated [18]; HIV viremia was classified as detectable if any other result was obtained.

Both naïve and HCV treatment-experienced patients were included. Previously failed antiviral treatment included therapy with interferon (standard or pegylated) as monotherapy or with ribavirin, according to the current international guidelines at the start of HCV treatment. Any virological response that was different from SVR was classified as having no response to antiviral treatment.

HCV RNA genotypes were determined using the VERSANT ${ }^{\circledast}$ HCV genotype 2.0 assay (INNOLiPA, Innogenetics, Belgium). HIV and HCV plasma viral loads (copies/mL and IU/mL, respectively) were evaluated using the Abbott Real-Time assay (Abbott Molecular Inc., Des Plaines, IL). 


\section{Study of liver fibrosis}

LS was measured by TE (FibroScan ${ }^{\oplus}$; Echosens, Paris, France). Significant liver fibrosis was defined as an LS of at least $7.1 \mathrm{kPa}[19,20]$. At least 10 successful measurements were performed on each patient; the result was considered valid when the interquartile range was lower than $30 \%$ of the median and a minimum success rate of $60 \%$ was obtained. Patients had been fasting for at least $8 \mathrm{~h}$ when TE was performed. An expert examiner carried out the LS assessments [21].

\section{Statistical analysis}

Conventional descriptive statistics were applied to describe the characteristics of the HIV-monoinfected subjects and the $\mathrm{HIV} / \mathrm{HCV}$ coinfected patients. Continuous data were expressed as mean and standard deviation and were compared using Student's $t$-test, while categorical data were compared using Fisher's exact test. In addition, the variables were submitted to a pairwise correlation analysis using Pearson's linear model to outline the underlying link pattern in the study population, and a logistic regression analysis was performed using the value of $\mathrm{LS}>7.1 \mathrm{kPa}$ as the dependent variable. Then, a linear regression model was set up with lkpa (LS value after $\log _{10}$ transformation) as the dependent variable. The mathematical model is a linear predictor; the final result was the predicted value of TE (expressed as lkpa) in a single patient and it was obtained by using the algebraic sum of each clinical variable multiplied by its own coefficient and of the intercept value. A locally weighted regression was applied for the empirical validation of the model. A regression analysis of predicted lkpa values versus observed lkpa values was also performed and the characteristics of the left outliers (patients with predicted values that were higher than or comparable to the observed values) and of the right outliers (patients with predicted values that were lower than the observed values) were analyzed using the chi-square test with no continuity correction and Student's $t$-test. Analyses were conducted using Stata software version 14.0 (College Station, Texas), and a P-value $<0.05$ guided the statistical interpretation.

\section{Results}

A total of 413 patients underwent a TE; a complete description of the selection process is summarized in Fig. 1. Overall, 251 of the 277 (90.6\%) patients were suitable for the main analysis (T1 study time); 26 patients were not included in the study because of a discordant plasma HIV viremia result at $\mathrm{T} 1$ and at T0 (21 patients had successful virological suppression at T0 and detectable viremia 12 months before TE).

The group of 251 patients included $178 \mathrm{HIV}$-monoinfected patients (124 with undetectable HIV RNA and 54 with detectable HIV RNA) and $73 \mathrm{HIV} / \mathrm{HCV}$ coinfected subjects (54 with undetectable HIV RNA and 19 with detectable HIV RNA). The demographic and viro-immunological

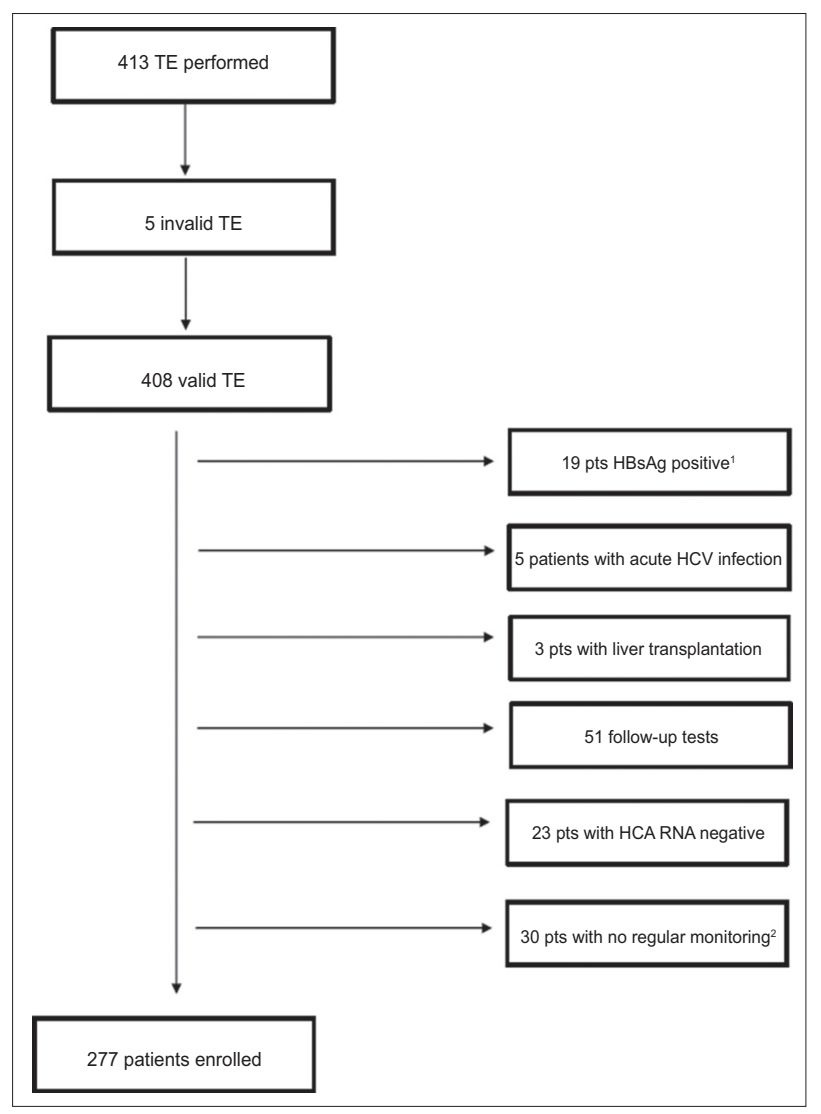

Figure 1 Flow chart describing the selection of the study patients ${ }^{1}$ Alcohol abuse in 5 patients

${ }^{2}$ Therapy with didanosine, stavudine or zidovudine in 3 patients TE, transient elastography

characteristics of all the patients included in the study are presented in Table 1. Patients with HIV/HCV coinfection had a significantly higher $\mathrm{LS}$ value $(\mathrm{P}<0.0001)$, a greater incidence of significant fibrosis $(\mathrm{P}<0.0001)$, higher AST and alanine aminotransferase values $(\mathrm{P}<0.0001)$, and a lower number of CD4+ cell counts at nadir $(\mathrm{P}=0.003)$.

The 36-month study period was available for 154 subjects (61.3\%), including 41 subjects (26.6\%) with $\mathrm{HIV} / \mathrm{HCV}$ coinfection and 113 subjects (73.4\%) with HIV monoinfection. Most patients were Caucasian (96.8\%) and on ART (89.6\%). The HCV genotype was available for 72 of the 73 patients with a 12-month study duration; 41 of these subjects (56.9\%) had genotype 1 infection. The mean HCV RNA level was comparable in coinfected patients with detectable pHIV and with undetectable pHIV $(1,021,736 \mathrm{IU} / \mathrm{mL}, 95 \%$ confidence interval [CI] 393,401-2,653,638 IU/mL and 1,216,888 IU/mL, 95\%CI 797,099-1,857,756 IU/mL, respectively; $\mathrm{P}=0.69)$. Only a few HIV/HCV patients (14 of 73, 19.2\%) had been previously treated with an interferon-based regimen. The mean LS was higher in $\mathrm{HIV} / \mathrm{HCV}$-coinfected patients $(\mathrm{P}<0.0001)$; most HIV-monoinfected patients (91\%) had an LS value $\leq 7.1 \mathrm{kPa}$. No significant differences in LS values were found between patients classified as having detectable or undetectable plasma HIV viremia, while HIV/HCV patients had higher LS values than monoinfected subjects, regardless of plasma HIV viremia 
Table 1 Characteristics of the 178 HIV-monoinfected subjects and of the 73 HIV HCV coinfected patients

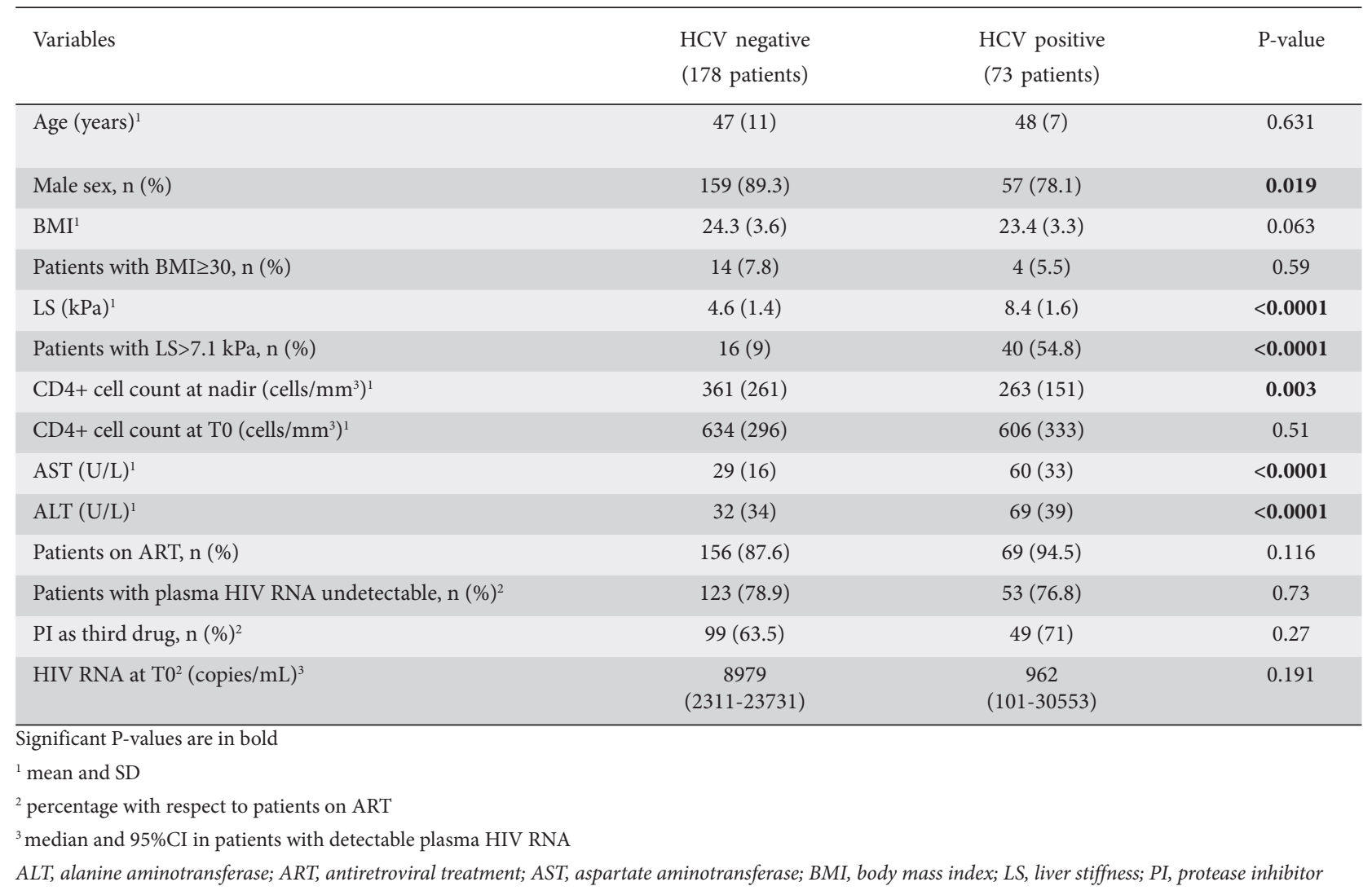

(Fig. 2). There was a significant correlation between lkpa and age $(\mathrm{P}=0.025)$, HCV coinfection $(\mathrm{P}<0.0001)$ and AST $(\mathrm{P}<0.0001)$. The quadratic variable "bmi2" was added to the linear regression model in order to investigate the hypothesis of a non-linear correlation between lkpa and body mass index (BMI) and this hypothesis was confirmed $(\mathrm{P}=0.026)$; the other variables failed to reach significant $\mathrm{P}$-values, including the successful suppression of HIV viremia at T1 and T2. This last finding was confirmed using logistic regression; this statistical approach revealed a positive correlation between an LS value $>7.1 \mathrm{kPa}$ and $\mathrm{BMI}(\mathrm{P}=0.006), \mathrm{BMI}$ as a quadratic variable $(\mathrm{P}=0.003)$, HCV coinfection $(\mathrm{P}<0.0001$ and AST $(\mathrm{P}=0.001)$. The final linear regression model data are reported in Table 2; the mean predicted values were $4.69 \mathrm{kPa}$ (95\%CI 4.44-4.95 $\mathrm{kPa})$ in patients with HIV monoinfection and $8.39 \mathrm{kPa}(95 \% \mathrm{CI}$ 7.70-9.15 kPa) in subjects with HIV/HCV coinfection. Fig. 3 depicts the effects of $\mathrm{HCV}$ infection and BMI on the original LS data and on the model-based predictions.

Following the linear regression model, an analysis was performed to describe bivariate normal distributions for predicted and observed LS values in patients with and without HCV coinfection. Two subgroups of outliers were identified in the group with HIV monoinfection (8 patients in each subgroup, 9\% of HIV-monoinfected patients) (Fig. 4). The predicted LS values included in the left outlier group were higher than or comparable to the observed LS values; conversely, the predicted LS data in the right outlier group were lower than the observed LS values. Patients included in the right outlier cohort had more frequent undetectable plasma HIV RNA (62.5\% versus $12.5 \%, \mathrm{P}=0.03$ ) and lower mean AST (33 U/l versus $89 \mathrm{U} / \mathrm{l}, 95 \% \mathrm{CI}$ of the difference $40-81 \mathrm{U} / \mathrm{l}$, $\mathrm{P}<0.0001$. Notably, the mean BMI was greater than 25 in both left outlier (28.6) and right outlier (29.6) groups (95\%CI for combined groups 26.7-31.4).

\section{Discussion}

We performed a linear model analysis to describe the correlations between clinical and viro-immunological variables and LS measurement (LSM) in a cohort of patients with HIV infection or with HIV/HCV coinfection, focusing on the role of plasma HIV viremia detectability or undetectability during two different study periods (12 and 36 months before LSM). In the overall study population, no correlation was reported for either HIV-monoinfected patients or subjects with HCV coinfection. Consistently with our results, Merchante et al [15] reported that HIV viremia (binary variable, $<200$ copies $/ \mathrm{mL}$ versus $>200$ copies $/ \mathrm{mL}$ ) at the time of TE is not a factor that is associated with an abnormal LS value (defined as $>7.2 \mathrm{kPa}$ in a cross-sectional study including only HIV-monoinfected subjects). Conversely, Mohr et al [22] showed that detectable HIV viremia for a 


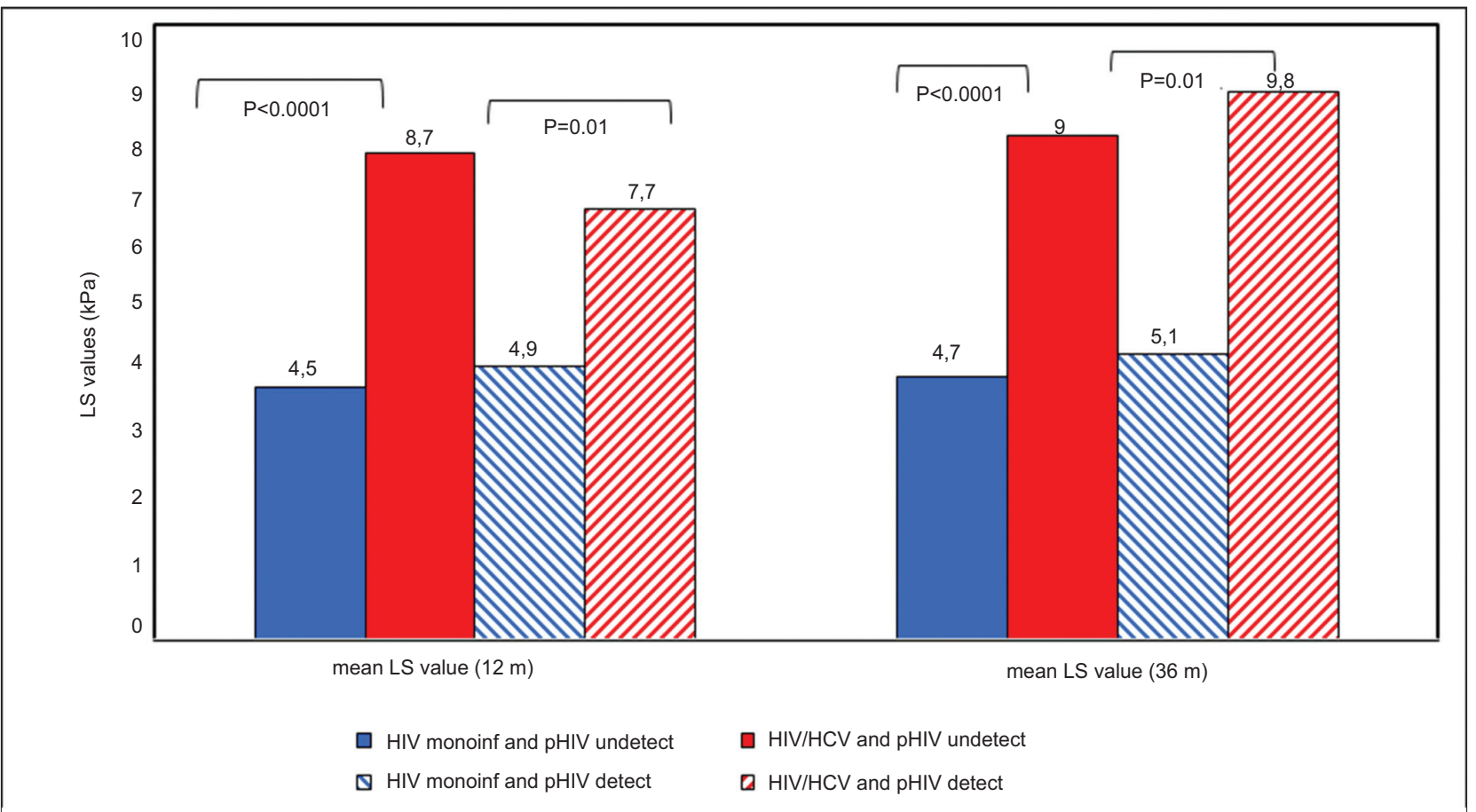

Figure 2 Liver stiffness values in HIV-monoinfected patients and in HIV/HCV patients according to plasma HIV RNA detectability or undetectability in the 12 months or 36 months before transient elastography

LS, liver stiffness; $k P a$, kilopascal; pHIV, plasma HIV RNA; m, months

Table 2 Linear regression model with lkpa (liver stiffness absolute value after $\log _{10}$ transformation), as dependent variable

\begin{tabular}{|c|c|c|c|c|c|c|}
\hline lkpa & Coefficient & Standard error & $\mathrm{t}$ & $\mathrm{P}>\mathrm{t}$ & \multicolumn{2}{|c|}{$95 \% \mathrm{CI}$} \\
\hline Age (years) & 0.0021796 & 0.0009666 & 2.25 & 0.025 & 0.0002748 & 0.0040844 \\
\hline Male sex & -0.0366232 & 0.0325936 & -1.12 & 0.262 & -0.1008542 & 0.0276077 \\
\hline HIV & 0.0202064 & 0.0250061 & 0.81 & 0.420 & -0.0290721 & 0.0694849 \\
\hline $\mathrm{HCV}$ & 0.1490692 & 0.0265554 & 5.61 & 0.000 & 0.0967376 & 0.2014008 \\
\hline Nadir CD4 & -0.000035 & 0.0000513 & -0.68 & 0.496 & -0.0001362 & 0.0000662 \\
\hline CD4 & $-7.53 \mathrm{E}-06$ & 0.0000401 & -0.19 & 0.851 & -0.0000865 & 0.0000714 \\
\hline BMI & -0.0530044 & 0.0280289 & -1.89 & 0.060 & -0.1082398 & 0.0022309 \\
\hline BMI2 & 0.0012249 & 0.0005458 & 2.24 & 0.026 & 0.0001492 & 0.0023006 \\
\hline AST & 0.0035958 & 0.0004461 & 8.06 & 0.000 & 0.0027167 & 0.0044749 \\
\hline Intercept & 1.053148 & 0.3531909 & 2.98 & 0.003 & 0.357129 & 1.749167 \\
\hline
\end{tabular}

Prob $>\mathrm{F}=0.0000 . \mathrm{R}^{2}=0.4971$

ALT, alanine aminotransferase; ART, antiretroviral treatment; AST, aspartate aminotransferase; BMI, body mass index; CD4, CD4+ cell count (cells/mm ${ }^{3}$ );

HIV, plasma HIV RNA undetectable; LS, liver stiffness; Nadir CD4: CD4+ cell count (cells $\left./ \mathrm{mm}^{3}\right)$ at nadir; Std. Err, standard error

period of more than 2 years was associated with higher LS values in naïve HIV-monoinfected patients; in this study, the subjects were classified as having plasma HIV viremia either greater than 40 copies/mL or undetectable. We were able to evaluate the role of two periods of different length (12 and 36 months) providing the same result. Moreover, the enrolled HIV viremic patients were both naïve and unresponsive to ART; a possible effect of an ART regimen with suboptimal efficacy cannot be excluded. Notably, both in our study and in Mohr's, there were no correlations found in patients with $\mathrm{HIV} / \mathrm{HCV}$ coinfection.

The plasma HIV viremia burden may play a role in explaining the differences between these results. Matthews et al [23] showed an association between HIV viremia and LS value in a population of naïve patients who had a median HIV RNA $\log _{10}$ copies of 4.4 ( $3.9 \log _{10}$ copies/mL in our study); only $3.9 \%$ of the participants had undetectable viremia (the cutoff was set at $\leq 400$ copies $/ \mathrm{mL}$, while it was 50 copies $/ \mathrm{mL}$ 


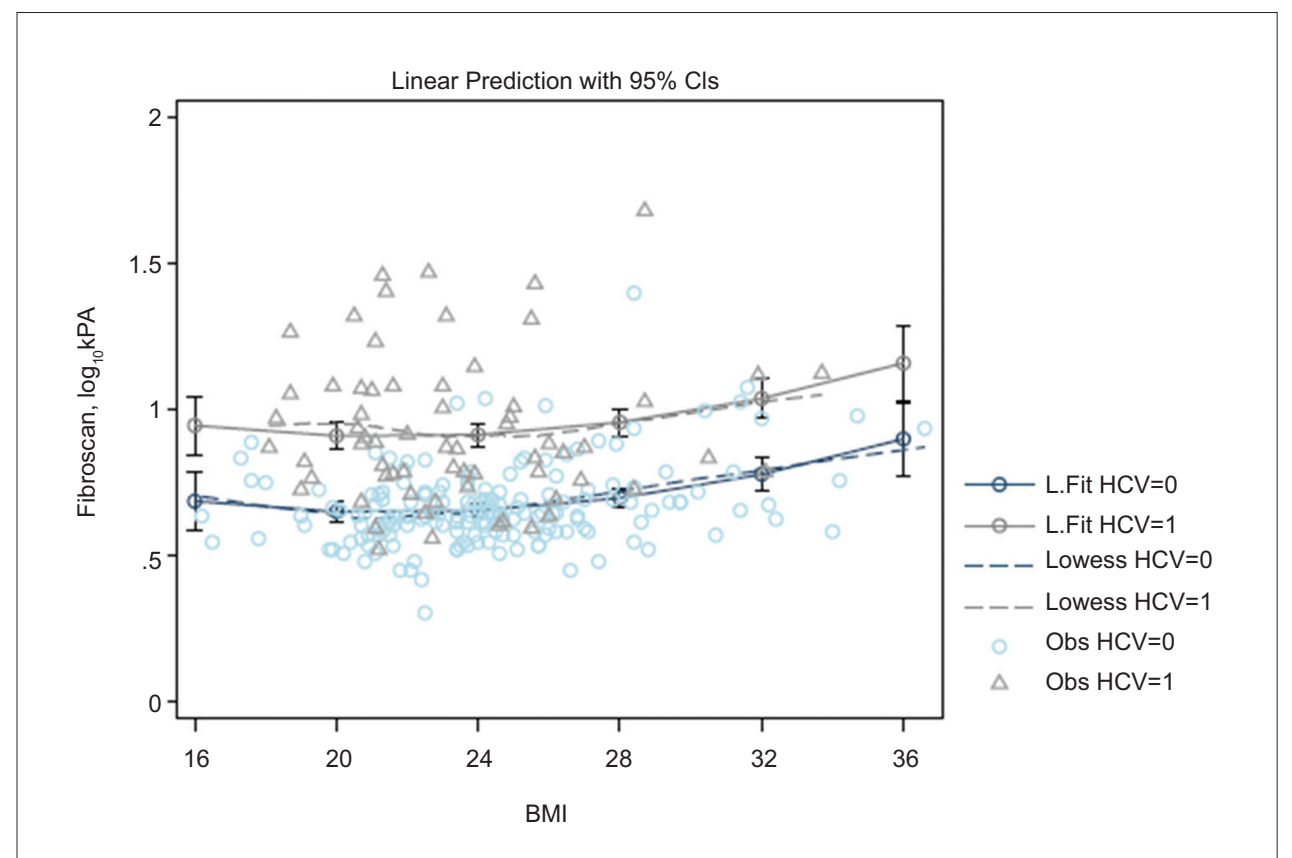

Figure 3 Linear model representation including the three main variables, $\log _{10}(\mathrm{kPa}), \mathrm{BMI}$, and HCV. The Figure depicts the effects of HCV infection and BMI on the Fibroscan values on the original data and on the model-based predictions BMI, body mass index; CI, confidence interval; L. Fit, linear fit; Lowess, locally weighted regression; Obs, observations; HCV0, HIV patient HCV-negative; HCV 1, HIV patient HCV-positive

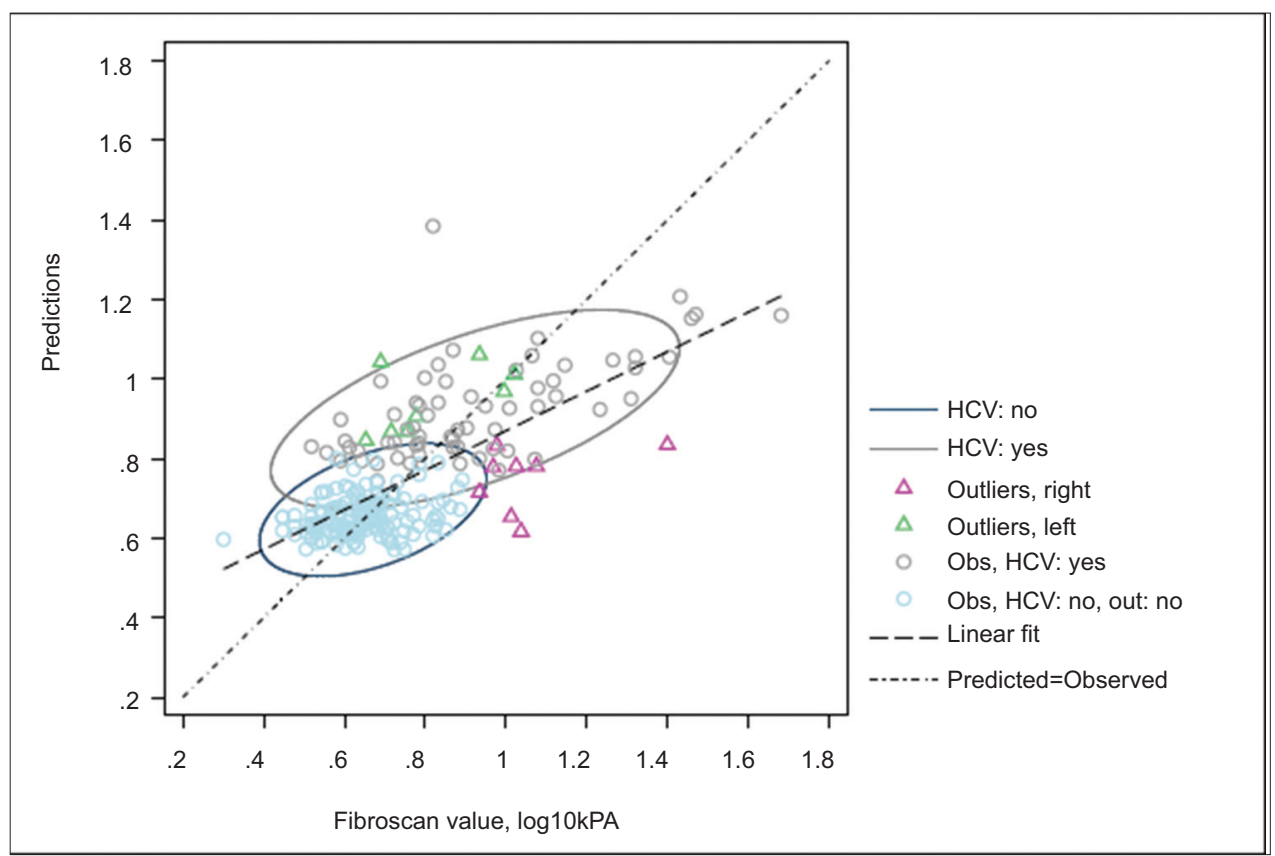

Figure 4 Graph describing the linear fit between predictions and observed Fibroscan values.

The reference line where predictions correspond to observations is also shown. The ellipses indicate bivariate normal distributions for predictions and observed Fibroscan values. Each of them correspond to a probability of $86 \%$; they account for the two subpopulations according to HCV status. Outliers, left: green; outliers, right, magenta;

Obs, observations; HCV 0, HIV patient HCV-negative; HCV 1, HIV patient HCV-positive; Out, outliers

in our study). Moreover, higher LS values were correlated with higher $\log _{10}$ HIV RNA values and a threshold effect that was defined as the upper limit of the first two quartiles
(19,999 copies/mL) was described; our median values were under this threshold (8979 copies/mL in HIV-monoinfected patients and 962 copies/mL in HIV/HCV-coinfected subjects). 
A role for the HIV RNA level in determining liver disease was reported by Towner et al [24] in a cohort study involving 20,775 HIV-positive subjects; the authors demonstrated a higher rate of hepatic dysfunction and hepatic dysfunctionrelated death in the case of plasma HIV RNA $>500$ copies $/ \mathrm{mL}$, while the risk increased with higher HIV RNA levels. A plasma HIV RNA value $<500$ copies/mL was shown to protect against liver fibrosis progression (determined with FIB-4 and AST-toplatelet ratio index scores) in a cohort of naïve patients who were starting highly active ART [25]; conversely, a median $12 \%$ increase in FIB-4 was associated with a 1 log increase in HIV RNA in the study conducted by Forrester et al [26].

The course of liver disease is largely unpredictable on a case-by-case basis, because liver fibrosis is a multifactorial process and the viscoelasticity of the liver may be influenced by inflammatory processes, as demonstrated in post-livertransplant acute cellular rejection [27]. Our statistical model identified a group of HIV-monoinfected patients with LS values that were discordant with respect to the predicted values; $\mathrm{HCV}$ infection had a much stronger hepatic damage capacity than did HIV infection, and this probably justified the absence of coinfected patients among the left and right outliers. The mean BMI was $\geq 25$ in the left outliers (the predicted LS value was higher than or comparable to the observed LS value) and in the right outliers (the observed LS value was higher than the predicted value); increased levels of inflammatory mediators have been described in subjects with HIV who were overweight and this could have perturbed the model [28]. Liver fibrosis is associated with higher BMI values in HIV-monoinfected subjects [29], and we confirmed this correlation using logistic regression in our cohort; however, both left and right outlier subjects were overweight. Almost all right outlier patients (87.5\%) had plasma HIV RNA levels that were undetectable in the 12 months before TE, which is in apparent contradiction to the absence of a correlation between the LS value and HIV viremia. Furthermore, HIV RNA is not the only virological parameter that can be used to evaluate HIV infection; cellular HIV DNA constitutes the viral reservoir and is detectable in peripheral mononuclear blood cells in patients with longterm suppressed viremia [30-32]. Recently, HIV DNA was also identified in the hepatic tissue of patients who died while they were on ART and who had undetectable levels of HIV RNA [33].

TE results are currently interpreted as a range in clinical practice, since this provides a more reliable correlation with the degree of fibrosis [34]. We choose to explore the absolute LS value in our HIV-monoinfected patients in order to highlight the differences in a population whose LS values were almost all included in the F0-F1 class of fibrosis (LSM $<7.1$ ). No selection bias was evident; our study population had an LSM value comparable to that of previously described cohorts of HIV-positive patients, ranging from 3.9-4.9 $\mathrm{kPa}[14,15,35]$. The main limits of our study are the influence of intra-observer TE reproducibility and the low number of outlier patients. All of the TEs were performed by the same expert operator and only 5 of the 413 patients who were screened (1.2\%) were excluded from the study because of an invalid TE, so good reproducibility was expected [36]. One strength of our study

\section{Summary Box}

\section{What is already known:}

- HIV may be directly responsible for liver damage

- Data on the influence of ongoing plasma HIV viremia on liver fibrosis progression are discordant, possibly because of differences in study design and patient selection

- Transient elastography is more reliable than the aspartate aminotransferase-to-platelet ratio index and Fibrosis-4 score for staging liver fibrosis in $\mathrm{HIV} / \mathrm{HCV}$-coinfected patients

\section{What the new findings are:}

- The absolute value of liver stiffness (LS) has no correlation with short- or long-term plasma HIV RNA replication in either immunocompetent HIVmonoinfected subjects or $\mathrm{HIV} / \mathrm{HCV}$-coinfected patients

- No significant difference in LS value was found between patients classified by detectable or undetectable plasma HIV viremia, while HIV/HCV patients had higher LS values than did monoinfected subjects, regardless of plasma HIV viremia values

- A minority of HIV-monoinfected patients showed LS values discordant with those predicted by the linear regression model

was the careful selection of patients; there were no HBsAgpositive subjects included, patients with HCV coinfection were all HCV RNA-positive and almost all of the patients were Caucasian. The independent predictive role of race has scarcely been studied, but Hispanic/Latino ethnicity was independently associated with higher TE scores in HIV patients [23], and HIV coinfection was predictive of early fibrosis in $\mathrm{HCV}$ positive African Americans [37].

In conclusion, the present study demonstrated that LS did not correlate with ongoing HIV replication during 12- and 36-month study periods in immunocompetent HIV/HCVcoinfected patients and in HIV-monoinfected subjects.

\section{References}

1. Andreoni M, Giacometti A, Maida I, Meraviglia P, Ripamonti D, Sarmati L. HIV-HCV co-infection: epidemiology, pathogenesis and therapeutic implications. Eur Rev Med Pharmacol Sci 2012;16:1473-1483.

2. Torti C, Lapadula G, Casari S, et al; EPOKA-MASTER Study Group. Incidence and risk factors for liver enzyme elevation during highly active antiretroviral therapy in HIV-HCV co-infected 
patients: results from the Italian EPOKA-MASTER Cohort. BMC Infect Dis 2005;5:58.

3. Martín-Carbonero L, Benhamou Y, Puoti M, et al. Incidence and predictors of severe liver fibrosis in human immunodeficiency virus-infected patients with chronic hepatitis C: a European collaborative study. Clin Infect Dis 2004;38:128-133.

4. Wyles DL, Sulkowski MS, Dieterich D. Management of hepatitis C/ HIV coinfection in the era of highly effective hepatitis $C$ virus directacting antiviral therapy. Clin Infect Dis 2016;63 Suppl 1:S3-S11.

5. Cotte L, Pugliese P, Valantin MA, et al; Dat'AIDS study Group. Hepatitis C treatment initiation in HIV-HCV coinfected patients. BMC Infect Dis 2016;16:345.

6. Günthard HF, Saag MS, Benson CA, et al. Antiretroviral drugs for treatment and prevention of HIV infection in adults: 2016 Recommendations of the International Antiviral Society-USA Panel. JAMA 2016;316:191-210.

7. Bruno R, Galastri S, Sacchi P, et al. gp120 modulates the biology of human hepatic stellate cells: a link between HIV infection and liver fibrogenesis. Gut 2010;59:513-520.

8. Gupta D, Rani M, Khan N, Jameel S. HIV-1 infected peripheral blood mononuclear cells modulate the fibrogenic activity of hepatic stellate cells through secreted TGF- $\beta$ and JNK signaling. PLoS One 2014;9:e91569.

9. Lee FJ, Amin J, Carr A. Efficacy of initial antiretroviral therapy for HIV-1 infection in adults: a systematic review and metaanalysis of 114 studies with up to 144 weeks' follow-up. PLoS One 2014;9:e97482.

10. Kirk GD, Astemborski J, Mehta SH, et al. Assessment of liver fibrosis by transient elastography in persons with hepatitis $\mathrm{C}$ virus infection or HIV-hepatitis C virus coinfection. Clin Infect Dis 2009;48:963-972.

11. Wandeler G, Mulenga L, Vinikoor MJ, et al; for IeDEA-Southern Africa and the Swiss HIV Cohort Study. Liver fibrosis in treatmentnaive HIV-infected and HIV/HBV co-infected patients: Zambia and Switzerland compared. Int J Infect Dis 2016;51:97-102.

12. Njei B, McCarty TR, Luk J, Ewelukwa O, Ditah I, Lim JK. Use of transient elastography in patients with HIV-HCV coinfection: A systematic review and meta-analysis. J Gastroenterol Hepatol 2016;31:1684-1693.

13. Han SH, Kim SU, Kim CO, et al. Abnormal liver stiffness assessed using transient elastography (Fibroscan ${ }^{\circ}$ ) in HIV-infected patients without $\mathrm{HBV} / \mathrm{HCV}$ coinfection receiving combined antiretroviral treatment. PLoS One 2013;8:e52720.

14. Brescini L, Orsetti E, Gesuita R, et al. Evaluating liver fibrosis by transient elastometry in patients with HIV-HCV coinfection and monoinfection. Hepat Mon 2014;14:e15426.

15. Merchante N, Pérez-Camacho I, Mira JA, et al; Grupo Andaluz para el Estudio de las Hepatitis Víricas de la Sociedad Andaluza de Enfermedades Infecciosas. Prevalence and risk factors for abnormal liver stiffness in HIV-infected patients without viral hepatitis coinfection: role of didanosine. Antivir Ther 2010;15:753-763.

16. Schmid P, Bregenzer A, Huber M, et al; Swiss HIV Cohort Study. Progression of liver fibrosis in HIV/HCV co-infection: a comparison between non-invasive assessment methods and liver biopsy. PLoS One 2015;10:e138838.

17. Passos AM, Treitinger A, Spada C. An overview of the mechanisms of HIV-related thrombocytopenia. Acta Haematol 2010;124:13-18.

18. Grennan JT, Loutfy MR, Su D, et al; CANOC Collaboration. Magnitude of virologic blips is associated with a higher risk for virologic rebound in HIV-infected individuals: a recurrent events analysis. J Infect Dis 2012;205:1230-1238.

19. Morse CG, McLaughlin M, Proschan M, et al. Transient elastography for the detection of hepatic fibrosis in HIV-monoinfected adults with elevated aminotransferases on antiretroviral therapy. AIDS 2015;29:2297-2302.

20. Castéra L, Vergniol J, Foucher J, et al. Prospective comparison of transient elastography, Fibrotest, APRI, and liver biopsy for the assessment of fibrosis in chronic hepatitis C. Gastroenterology 2005; 128:343-350.

21. Lucidarme D, Foucher J, Le Bail B, et al. Factors of accuracy of transient elastography (fibroscan) for the diagnosis of liver fibrosis in chronic hepatitis C. Hepatology 2009;49:1083-1089.

22. Mohr R, Schierwagen R, Schwarze-Zander C, et al. Liver fibrosis in HIV patients receiving a modern cART: which factors play a role? Medicine (Baltimore) 2015;94:e2127.

23. Matthews GV, Neuhaus J, Bhagani S, et al. Baseline prevalence and predictors of liver fibrosis among HIV-positive individuals: a substudy of the INSIGHT Strategic Timing of AntiRetroviral Treatment (START) trial. HIV Med 2015;16 Suppl 1:129-136.

24. Towner WJ, Xu L, Leyden WA, et al. The effect of HIV infection, immunodeficiency, and antiretroviral therapy on the risk of hepatic dysfunction. J Acquir Immune Defic Syndr 2012;60:321-327.

25. Mendeni M, Focà E, Gotti D, et al. Evaluation of liver fibrosis: concordance analysis between noninvasive scores (APRI and FIB-4) evolution and predictors in a cohort of HIV-infected patients without hepatitis C and B infection. Clin Infect Dis 2011;52:1164-1173.

26. Forrester JE, Rhee MS, McGovern BH, Sterling RK, Knox TA, Terrin N. The association of HIV viral load with indirect markers of liver injury. J Viral Hepat 2012;19:e202-e211.

27. Crespo G, Castro-Narro G, García-Juárez I, et al. Usefulness of liver stiffness measurement during acute cellular rejection in liver transplantation. Liver Transpl 2016;22:298-304.

28. Koethe JR, Dee K, Bian A, et al. Circulating interleukin-6, soluble $\mathrm{CD} 14$, and other inflammation biomarker levels differ between obese and nonobese HIV-infected adults on antiretroviral therapy. AIDS Res Hum Retroviruses 2013;29:1019-1025.

29. Lombardi R, Sambatakou H, Mariolis I, Cokkinos D, Papatheodoridis GV, Tsochatzis EA. Prevalence and predictors of liver steatosis and fibrosis in unselected patients with HIV monoinfection. Dig Liver Dis 2016;48:1471-1477.

30. Sarmati L, Parisi SG, Nicastri E, et al. Association between cellular human immunodeficiency virus DNA level and immunological parameters in patients with undetectable plasma viremia level during highly active antiretroviral therapy. J Clin Microbiol 2005;43:6183-6185.

31. Parisi SG, Andreis S, Mengoli C, et al. Baseline cellular HIV DNA load predicts HIV DNA decline and residual HIV plasma levels during effective antiretroviral therapy. J Clin Microbiol 2012;50:258-263.

32. Parisi SG, Sarmati L, Andreis S, et al. Strong and persistent correlation between baseline and follow-up HIV-DNA levels and residual viremia in a population of naive patients with more than 4 years of effective antiretroviral therapy. Clin Microbiol Infect 2015;21:288.e5-7.

33. Lamers SL, Rose R, Maidji E, et al. HIV DNA is frequently present within pathologic tissues evaluated at autopsy from combined antiretroviral therapy-treated patients with undetectable viral loads. J Virol 2016;90:8968-8983.

34. Sagnelli C, Martini S, Pisaturo M, et al. Liver fibrosis in human immunodeficiency virus/hepatitis $\mathrm{C}$ virus coinfection: Diagnostic methods and clinical impact. World J Hepatol 2015;7:2510-2521.

35. Sacchi P, Cima S, Corbella M, et al. Liver fibrosis, microbial translocation and immune activation markers in HIV and HCV infections and in HIV/HCV co-infection. Dig Liver Dis 2015;47:218-225.

36. Perazzo H, Fernandes FF, Soares JC, et al. Learning curve and intra/interobserver agreement of transient elastography in chronic hepatitis C patients with or without HIV co-infection. Clin Res Hepatol Gastroenterol 2016;40:73-82.

37. Silver D, Karnik G, Osinusi A, et al. Effect of HIV on liver fibrosis among HCV-infected African Americans. Clin Infect Dis 2013;56:1280-1283. 